\title{
NON-DEPOT ACTH FOR INFANTILE SPASMS
}

The effects and side-effects of non-depot ACTH therapy in 18 children with infantile spasms are reported from the Wilhelmina Children's Hospital, University of Utrecht, The Netherlands. In i.m. doses of $0.4 \mathrm{mg}$ bid for 4 weeks, followed by gradual withdrawal over 2 weeks, non-depot ACTH resulted in complete control of spasms and normalization of the EEG in 6 (33\%) patients, and a partial control in 5. Those with cryptogenic seizures responded whereas infants with congenital defects, excepting 2 with tuberous sclerosis, were refractory to treatment. Response to non-depot ACTH was comparable to that reported for depot $\mathrm{ACTH}$, the incidence of side-effects was lower, and a persistent hypercortisolism was not induced. (Kusse MN et al. The effect of non-depot ACTH $(1-24)$ on infantile spasms. Dev Med Child Neurol Dec 1993;35:1067-1073). (Respond: O van Nieuwenhuizen MD, PhD,Dept Child Neurology WKZ, Academisch Ziekenhuis Utecht, PO 85500, 3508 GA Utecht, The Netherlands).

COMMENT. Non-depot ACTH appears worthy of further trial in patients with West syndrome. As with depot ACTH, the dosage schedule may require controlled studies to establish optimal efficacy. Dosage based on surface area or body weight would seem more appropriate, if the mechanism of action is related to a direct effect on the brain, as suggested by these authors and by others. The relatively high frequency of serious side-effects sometimes reported with depot ACTH

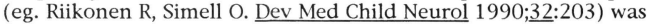
associated with a high dose regimen(80-140 IU daily for 6 weeks). I have favored the more conservative regimen with smaller, less toxic doses (10-20 IU daily for 2-3 weeks), a treatment schedule also followed in Japan. (see Millichap JG. Progress in Pediatric Neurology , Chicago, PNB Publ, 1991, pp 25-26, 30-34).

\section{ACTH EFFICACY IN SYMPTOMATIC INFANTILE SPASMS}

A retrospective evaluation of 26 case records of patients with diagnoses of symptomatic infantile spasms and classic hypsarrhythmia is reported from the Division of Pediatric Neurology, University of Minnesota Medical School, Minneapolis, MN. Seventeen (65\%) had complete control of spasms and 9 did not respond. Both responders and nonresponders received similar ACTH dosages ( 87.4 and $84.5 \mathrm{U} / \mathrm{m}^{2}$, respectively). High-dose ACTH $\left(>100 \mathrm{U} / \mathrm{m}^{2}\right.$ ) was not more effective than lower dose regimens. Favorable outcome was associated with late onset ( $>8$ months of age) and prompt treatment ( 1 month of onset). Responders either improved or did not deteriorate in development, whereas nonresponders were more impaired neurologically. (Sher PK, Sheikh MR. Therapeutic efficacy of ACTH in symptomatic infantile spasms with hypsarrhythmia. Pediatr Neurol Nov/Dec 1993;9:451-6). (Respond: Dr Sher, Division of Pediatric Neurology, Box 486 Mayo Building, Minneapolis, MN 55455).

COMMENT. The control of seizures in responders occurred in 1.6 weeks (0.5-6), and hypsarrhythmia disappeared in all. Despite the symptomatic nature of the infantile spasms and pre-treatment neurologic abnormalities, the results of moderate and relatively short duration ACTH dosage can be satisfactory provided seizure onset is delayed until after 4 months of age and treatment is initiated promptly. High dose regimens with increased risk of serious toxicity are 